\section{New editor appointed for Evidence-Based Dentistry}

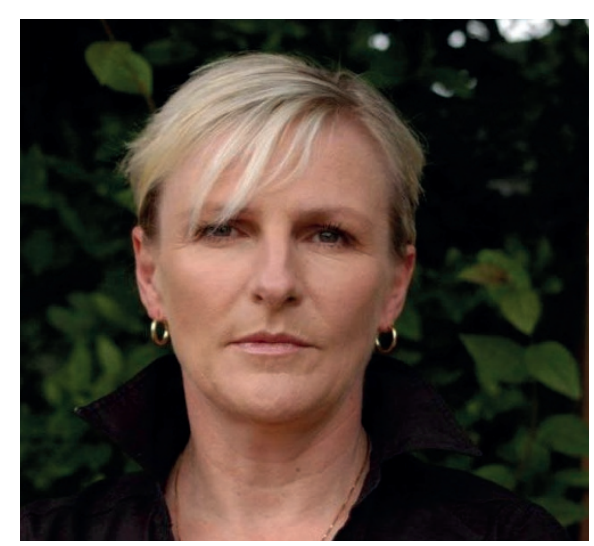

Professor Elizabeth Kay has been appointed as the new editor of the BDJ Portfolio journal Evidence-Based Dentistry (EBD).

Kay, who qualified as a dentist in 1982, has a long and distinguished career in dental public health and dental research and is a longstanding member of the BDJ Editorial Board.

She is the author of 200 research and professional papers, six books, and two book chapters and was previously Scientific Advisor to the BDA.

Kay was awarded a MBE in 2017 and is currently the Foundation Dean at the Peninsula Dental School at Plymouth University and Faculty Associate Dean for Equality and Inclusion. She will take on the position from current Editor, Derek Richards, in February 2019.

'I'm really excited about the new post and to have the privilege of working with some excellent people, said Kay.

'I have spent quite a long career trying to do research and translate it so that it's relevant to practitioners who are delivering good dental care to the population.

'I've been a great proponent of evidencebased practice and the evidence base being used properly ever since I did my PhD. I've been very involved with NICE [National Institute for Health and Care Excellence] so I'm very used to reviewing and trying to pull together complex and complicated and sometimes conflicting evidence and that's a real role for the journal of Evidence-Based Dentistry.'

Stephen Hancocks, Editor-in-Chief of the $B D J$ welcomed the appointment, saying: ' $\mathrm{Liz}$ is a great fit as the next editor of $E B D$ and I am delighted that she will be working with us to make even more of the journal based on its strong foundation and robust reputation.'

\section{BDA Benevolent Fund - what, who, why, when, how and where?}

Dr Allan Franklin, Honorary Secretary of the BDA Benevolent Fund, shares the 'Why's and

'How's', to raise awareness of the important role of the charity.

\section{What is the charity about?}

The BDA Benevolent Fund was established late in the nineteenth century, and I came along about a century later! Things have changed a fair bit over the almost 140 years, but the ethos remains the same - to keep a roof over our beneficiaries' heads and to help them get back on the road to success. Success represents different things for different people - for some it means getting back to work as a dentist, for others it means following a new career path.

\section{Who is eligible?}

Despite the name - BDA Benevolent Fund - you do not need to be a BDA member to get help from us. Irrespective of affiliation, we can provide financial aid to dental students, dentists and their families in need, whether they are in training, in practice, have left the profession or are retired.

\section{Why is it needed?}

Circumstances can change in the blink of an eye. We have no control over illness or accident, which, very sadly, can be life-changing. Likewise, mental health difficulties can easily result in an inability to work, either in the short- or long-term. Then there are complaints made to the GDC that can take several months to resolve and sometimes mean the dental professional cannot work in the interim. All these problems can lead to many struggles in life, including financial hardship, which is where the charity comes in.

\section{When can help be given?}

We help applicants as soon as we have established their need. This involves preparing a report on their request and considering it at one of the charity's Trustee meetings. Our General Manager or a Trustee may also visit them to better understand how we can assist and what financial support will help overcome their difficult situation.

There is no set limit to how long we will support someone, but we do try to help grant recipients to get back on their feet as quickly as possible. Sometimes all that is needed is a one-off payment, for a deposit or for their ARF (annual retention fee), for example. On occasion, we help for a few months or years and, in a few exceptional cases, we stay by their side for decades. The bottom line is that we will never walk away from an eligible applicant in financial need.

\section{How is support provided?}

The type of support the charity can offer varies according to individual needs but may include:

- Regular payments towards daily living costs, for instance food, utility bills, etc

- One-off help to meet a particular requirement, such as fixing a leaky roof

- Back-to-work funding, for example a grant for retraining expenses, professional fees or indemnity costs.

\section{Where does the charity operate?}

The charity is based in London, in office space and facilities gifted by the BDA, which allows us to keep costs down. However, our reach goes far beyond the capital, helping people living throughout the UK.

The BDA Benevolent Fund is here to support dentists and so, if you, or someone you know, is facing financial difficulties - for whatever reason - please contact BDA Benevolent Fund, in confidence, on 0207486 4994, or visit www.bdabenevolentfund.org.uk for more information. 